\title{
Measuring the Immeasurable: Understanding the Effectiveness of Anti-child Trafficking Transnational Advocacy Networks
}

\author{
Deanna Davy \\ University of Sydney
}

\begin{abstract}
Transnational advocacy networks' anti-child trafficking efforts have led to significant progress in the Mekong Subregion by bringing the child trafficking issue onto the global social policy agenda, resulting in new child protection legislation and improved inter-agency collaboration in the region. However, a significant gap in both the literature on TANs and TAN practice is the lack of monitoring and evaluation of TAN 'effectiveness'. This article discusses the recent literature on TAN effectiveness and discusses the 'key elements' of TAN effectiveness, as highlighted by child trafficking experts operating in TANs in the Greater Mekong Subregion. Research into the area of TAN effectiveness is important for improving our knowledge of what TANs are achieving in terms of preventing child trafficking and protecting victims, as well as improving our knowledge of the different meanings and interpretations of TAN 'effectiveness'. Furthermore, research into this area is important for improving our understanding of how TANs are well positioned to provide an effective response to the child sex trafficking problem.
\end{abstract}

\section{Introduction}

In the Greater Mekong Subregion (GMS) transnational advocacy networks (TANs) have been forming since the 1990s to combat child trafficking for sexual exploitation. Child sex trafficking occurs in all Southeast Asian countries. In a region where the demand for young brides, adoptive infants, sex with children, images of child pornography, and cheap labour is strong, children may be trafficked at source or during migration, either en route or after reaching their destination. Origin, transit and destination countries for child trafficking exist throughout the Southeast Asia region with some countries characterised as origin, transit, or destination, and others encompassing all three (UNICEF, 2009, p. 19). Internal trafficking, from rural to urban centres and from small towns to big cities, is also a considerable dynamic although far less researched than cross-border trafficking. Complex push and pull factors including poverty, gender inequality, unemployment, and forced migration complicate the child sex trafficking issue.

Due to their transnational nature, and the diverse membership of government, nongovernment and UN agencies operating within TANs, these groups are well placed to lead campaigns against child sex trafficking. Anti-child trafficking TANs operating in the GMS 
have successfully lobbied for new legislation on the child trafficking problem, developed improved systems for protecting children, improved inter-agency cooperation on child trafficking and associated issues. Also, they have facilitated the development of a global social movement against child sex trafficking as demonstrated in the examples of UN.GIFT, the United Nations Inter-agency Project on Trafficking (UNIAP), global anti-trafficking campaigns such as the Child Wise and Body Shop campaign, and new extraterritorial legislation on child trafficking.

This article examines the important theme of the effectiveness of anti-child trafficking TANs in the GMS. The article first discusses the methods used for collecting data for this research. Next, it briefly summarises the definitions of child trafficking, and provides an overview of child trafficking estimates in the Southeast Asia region. It then provides a discussion of the recent literature on TANs, and an overview of the literature on TANs in Southeast Asia. The article finally discusses the research findings, including an examination of the barriers to measuring the effectiveness of TANs; the 'key elements' of TAN effectiveness that were identified by anti-child trafficking experts operating in TANs in the GMS; and the centrality of TANs in combating child sex trafficking. Research into the issue of TAN effectiveness is important for improving our understanding of the complex interplay between TAN partners, the importance of network structure, charismatic leaders, and information sharing. It is also important in order to better understand how TANs are well positioned to lead the fight against global social issues such as child trafficking.

\section{Methods}

I spent a period of six months based in Thailand in 2010 in order to collect data for this research. I conducted twenty-two interviews with anti-child trafficking experts employed in NGOs, UN agencies, TANs, and academia in Bangkok (Thailand), Pattaya (Thailand), Chiang Mai (Thailand) and Phnom Penh (Cambodia). The purpose of the semi-structured interviews was to build a complete picture of the child trafficking problem in Thailand and Cambodia; a picture of TANs and their diverse structures; an understanding of the antitrafficking advocacy strategies employed; campaign goals and highlights; and experts' impressions on TANs' effectiveness. Additional methodologies included process tracing and participant observation (performed while I was employed as a researcher at an international NGO in Bangkok and attending regional anti-trafficking fora, seminars and meetings). Due to the difficulties of quantifying a complex and transnational social problem, employing a 
qualitative research methodology allowed the exploration of normative and theoretical questions within the social science framework. The strategies employed illuminated complexities in the child sex trafficking issue, and also complexity in advocacy networking processes against child trafficking in Thailand and Cambodia, and diverse interpretations of TANs' 'effectiveness'.

Although this article discusses the issue of child sex trafficking as a global social issue, Thailand and Cambodia served as the primary country case studies for data collection and the analysis of TANs' activities. Through the study of these two countries and the TANs against child sex trafficking operating within them, interesting networking phenomena became evident including fluidity in TAN dynamics, goals and activities; the development of cohesive networks against trafficking; the collective sharing of resources, knowledge and expertise among network partners; and diverse manifestations and interpretations of TAN ‘success' and 'effectiveness' such as improved victim services, improved inter-agency cooperation, and the shaping of social policy on the child trafficking issue as a result of the collective advocacy efforts of these networks.

\section{Child sex trafficking definitions and estimates, and dynamics}

\section{Definitions}

Today the most widely accepted definition of human trafficking comes from the UN Protocol to Prevent, Suppress and Punish Trafficking in Persons, Especially Women and Children, supplementing the UN Convention against Transnational Organised Crime, better known as the Palermo Protocol (November 2000). The Palermo Protocol provides a widely used definition of trafficking:

a) 'Trafficking in persons' shall mean the recruitment, transportation, transfer, harbouring or receipt of persons, by means of the threat or use of force or other forms of coercion, of abduction, of fraud, of deception, of the abuse of power or of a position of vulnerability or of the giving or receiving of payments or benefits to achieve the consent of a person having control over another person, for the purpose of exploitation. Exploitation shall include, at a minimum, the exploitation of the prostitution of others or other forms of sexual exploitation, forced labour or services, slavery or practices similar to slavery, servitude or the removal of organs.

b) The consent of the victim of trafficking in persons to the intended exploitation set forth in the subparagraph (a) of this article shall be irrelevant where any of the means set forth in the subparagraph (a) have been used; 
c) The recruitment, transportation, transfer, harbouring or receipt of a child for the purpose of exploitation shall be considered 'trafficking in persons' even if this does not involve any of the means set forth in the subparagraph (a) of this article;

d) 'Child' shall mean any person under eighteen years of age.

As the Protocol implies, sexual trafficking refers to a specific subset of wider phenomena of human trafficking. It can be understood as the component of human trafficking that deals with the use of persons - almost exclusively young women and children - in prostitution and other forms of sexual exploitation. As subsection (b) of the Protocol clarifies, the use of whether a victim 'consents' or not is 'irrelevant'. In essence, the Protocol holds that consent cannot truly be given when acts such as fraud and deception are employed. Exploitation rather than consent is the central feature of the Palermo Protocol's definition. The emphasis on traffickers is also evident in the fact that the Palermo Protocol is a supplement to the UN Convention against Transnational Organised Crime. It is these organised criminal networks of traffickers that have played an instrumental role in the globalisation of sexual trafficking, however, the trafficking of children in the GMS operates as more of a cottage industry rather than a large-scale criminal enterprise as occurs in Eastern Europe.

Wylie and McRedmond (2010) argue that the adoption of the Palermo Protocol and its tripartite definition of trafficking as involving deceptive/coercive recruitment, movement and exploitation of a person, has driven the debate on trafficking forward and has been a crucial factor in states' recognition of human trafficking as a serious problem. The Palermo definition of 'trafficking' has provided an important step towards ensuring structure and cohesion in approaches to the prevention of trafficking and the prosecution of traffickers (UNODC, 2008). Advocacy organisations and TANs have, however, also pointed out that the definition reduces trafficking to a law and justice issue rather than a problem associated within the larger global issue of uneven wealth and resource distribution due to globalisation (Canadian Council for Refugees, 2009). The Palermo Protocol has highlighted the need for increased border security with the objective that prosecution of traffickers would curtail cross border smuggling. Such policies have, however, at times had negative effects. Instead of contributing to the eradication of trafficking, related government policy has instead forced the individuals who would previously have attempted to migrate legally, to turn to smugglers and traffickers to help them navigate the often difficult terrain across national borders to their point of destination (Marshall, 2001). This leaves open the very real possibility of migrating 
adults and children falling victim to the lure of traffickers. Piotrowicz (2008) has argued that 'the problem (or at least the limitation) of the Palermo Protocol is that it is aimed primarily at tackling the perpetrators of trafficking... However, from the victim's perspective, the Protocol offers only limited assistance with rather nebulous, aspirational obligations that leave much to be desired'. This then leaves the burden of attending to the concrete rights of, and assistance for, trafficking victims in the hands of individual states. Therefore, there is no uniform standard for the rights and reparations of victims (Brusca, 2011). What we therefore have in the Palermo Protocol is an instrument aimed at tackling trafficking through fighting the traffickers, with 'limited acknowledgement of the rights of the victims, who may need protection and assistance' (Piotrowicz, 2008).

A further criticism of the Palermo Protocol is that it uses a rigid notion of the 'child' which lacks any nuances (Huijsmans, 2008, p. 331). It defines the 'child' technically on the basis of age as any person below the age of 18 years and thus leaves no room for children's evolving capacities (Huijsmans, 2008). It also ignores dramatic sociocultural as well as socioeconomic heterogeneity hidden in the singular notion of the 'child' (Huijsmans, 2008, p. 331). A problem with the Palermo Protocol's definition of the 'child' is that by a priori rendering children's consent to ‘exploitation' irrelevant, it denies children any form of agency, even at a conceptual level (Huijsmans, 2008, p. 336). The result is that children are treated as passive victims of abuse in need of rescue rather than inviting more child-centred approaches to address child trafficking (Huijsmans, 2008, p. 336).

\section{Estimates}

The United Nations Inter-Agency Project on Human Trafficking (2008) states that there are no universally accepted estimates of child trafficking numbers throughout the world.

Difficulties in identifying victims and differences in applying trafficking definitions to local realities make such estimates virtually impossible. However, some commonly quoted figures provide some sense of the magnitude of the problem. UNICEF (2009) suggests that globally, about 10 million children, mainly girls, are subjected to various forms of sexual exploitation worldwide. A further one million children are estimated to enter the commercial sex trade each year (UNICEF, 2009). UNICEF (2009) further estimates that a third of all sex workers in Southeast Asia are between the ages of 12 and 17. Kristof (1996) similarly notes that more than a million girls and boys, aged 17 and younger, were engaged in forced prostitution in Asia. According to Child Wise (2007), an Australian NGO working on the human trafficking 
issue both domestically and internationally, more than 250000 sex tourists visit Asia each year, with 25 per cent coming from the United States, 16 per cent from Germany and 13 per cent from both Australia and the United Kingdom. This includes those seeking sex with children, a practice better known as child sex tourism, and those specifically targeting prepubescent children, that is, paedophilia (Peters, 2007).

The global and public policy response to human trafficking has been profound. As Wong (2004) suggests, from a poorly funded NGO women’s issue in the early 1980s, human trafficking has entered the global agenda of high politics, eliciting in recent years significant legislative and other action from the US Congress, the EU and the UN. While End Child Prostitution, Child Pornography and Trafficking of Children for Sexual Purposes (ECPAT) (2006) reports that, to date, there is no clear strategy to deal with the demand for sex with children, it is the political activism and campaigning of TANs that has influenced the promotion of child trafficking as an important issue for public and international policy concerns.

\section{Recent literature on the dynamics and activities of TANS}

Problems cannot be resolved by individual states or organisations acting alone, and today there exists a significant number of actors whose interests and capacities span national borders (Florini, 2000, p. 15). For Keck and Sikkink (1998) transnational networks operate as 'advocacy networks', producing a common discourse on particular contentious issues. TANs in today's society consist of partnerships between NGOs from both North and South, UN agencies, and, though frequently to a lesser extent, government partners. Inter-agency TANs such as UNIAP incorporate government, non-government, and UN agencies, while NGO networks such as ECPAT are composed of international and domestic NGOs. These networks often have a number of partners spanning the globe, a structure including a secretariat to coordinate partners, and common values that have brought the network partners together for a specific purpose. What these networks achieve is a new form of political space beyond the state that transcends state boundaries and defies the traditional notion that development actors are bounded by local or national scales (Morvaridi, 2005, p. 135).

TANs seek influence in many of the same ways that other political groups or social movements do. Since they are not powerful in a traditional sense of the word, they must use 
the power of their information, ideas and strategies to alter the information and value contexts within which states make policies (Keck \& Sikkink, 1999, p. 16). TANs’ powers of influence also stem from their ability to operate transnationally, that is, beyond borders, and to extend their advocacy to all groups. The value of Keck and Sikkink’s (1998) approach is that they define TANs as a unified web with overarching aims and strategies and in doing so they define the concept as a type of political actor worthy of academic and political attention. Keck and Sikkink (1998) see the local effectiveness of these global networks as built on three interrelated effects: Transmitting information, invoking norms, and shifting political venues. In a similar vein, Evans (2000) argues that networks gain their fundamental leverage from the global spread of certain basic norms centred on human dignity.

Transnational networks unite citizens across the world to advocate for certain global issues (Morvaridi, 2005, p. 135). TANs usually focus on one narrow issue that is of interest to all their participants while NGOs and other global activists typically have broad agendas focusing on a range of different human rights, environmental and other issues (Shawki, 2007, p. 12). Once established, TANs campaign using a number of different tactics: the collection and strategic use and dissemination of credible information, and pressure on governments and other powerful actors to uphold the values, norms and principles that they have pledged to respect (Shawki, 2007, p. 14).

In comparison to other relationships between organisations, TANs have the potential to provide a more flexible, flat and non-hierarchical means of exchange and interaction that promises to be more innovative, responsive and dynamic, while overcoming spatial separation and providing scale economies (Henry et al, 2004, p. 839). The perceived advantages of these kinds of networks fit with NGOs' ideologies concerning their presumed comparative advantage over the state and market. International NGOs and UN agencies seeking social transformation collaborate on a number of levels to influence global governance. They create and activate global networks, participate in multilateral arenas, facilitate inter-state cooperation, and act within states to influence policy and enhance public participation (Alger, 1997). Even in areas often considered to be the sole domain of states such as international security, TANs can play a role in shaping the agenda and contributing to policy change (Price, 1998). 
In a media-saturated global environment, the communicative power of TANs - the capacity to reach a global audience and shape international public opinion - is considerable (Held, 2002, p. 69). This is manifest in the ways the networks exert influence by exploiting distinctive political strategies including influencing public attitudes, interests and identities; redefining the agenda of local, national and global politics; providing communities and citizens with a voice in global decision-making fora; and seeking to make governments and corporations accountable for their actions and decisions (Held, 2002, p. 69). Although a decade old, as the network literature has demonstrated, TANs do a great many things including lobbying governments, standard-setting, monitoring of compliance with standards and laws, and naming and shaming norm violators (Keck and Sikkink, 1998). In the last decade many TANs have developed in the fields of advocacy and policy within the environmental movement, the women's movement and the human rights movement, amongst many others. Among successful transnational campaigns are the Jubilee 2000 Drop the Debt campaign, the AIDS campaign, the international coalition for the establishment of the International Criminal Court, the campaign against the Multilateral Agreement on Investment, and the Ottawa Convention banning landmines (Held, 2002, p. 69).

Yanacopulos explains that a key motivation for organisations, particularly NGOs, in forming networks and coalitions is their economies of scale (2005, p. 101). Advocacy at the global level is extremely expensive and no one organisation can afford to finance and support a global advocacy campaign (Yanacopulos, 2005, p. 101). This factor has influenced the strategic reconfigurations of organisations. Furthermore, information sharing and the specialisation of skills is also an essential cost saving and value-added element of forming networks and coalitions (Yanacopulos, 2005, p. 101). An additional benefit of networks is that they harness expertise through pooling research, staff, funds and resources. Another key network motivation is to take advantage of the strengths or comparative advantages of different NGOs as well as the expertise of the UN agency partners (Hudson, 2002, p. 411). Perhaps most important reason, however, is the collective weight that such cooperation can provide (Hudson, 2002, p. 411). As Baehr (1996) argues, by aligning, organisations can minimise overlapping endeavours and share resources. 


\section{Transnational advocacy networks in Southeast Asia}

While organised collective action is strong in certain regions of the world, transnational activism is a relatively new phenomenon in Southeast Asia. TANs have emerged in Asia in the past four decades in response to problems such as chronic poverty and inequality. The past twenty years have seen greater democracy take root in most of Asia, and there have been increased political freedoms, even in some tightly controlled societies such as China and Vietnam. The People’s Power movements, in the Philippines in 1986, in China in 1989, and mass demonstrations in Myanmar in 1988 and Thailand in 1992 and 2010, were a new symptom of a new approach to politics spurned by the growth of a new middle class.

Transnational activism has emerged in Southeast Asia as a response to socioeconomic and political processes associated with globalisation, as well as a consequence of relative and limited political liberalisation that has characterised some Southeast Asian countries (Caouette, 2007, p. 150). As Loh and Ojendal note, 'although the Southeast Asian countries enjoyed unprecedented high rates of economic growth in the 1980s and 1990s, and experienced pluralisation of their societies, nevertheless, the state authorities continued to dominate over their societies' (2005, p.3). Transnational activist organisations in Southeast Asia have established themselves in countries where relative political space existed, or at least allowed, for global organising (Caouette, 2007, p. 150).

In recent decades in Southeast Asia, as in many other regions of the world, there has been a growing tendency to organise and work transnationally. The Philippines, Thailand, Indonesia and increasingly Malaysia host various forms of transnational activist organisations (Caouette, 2006, p. 6). Today Bangkok, Manila, and Jakarta act as 'nodes of transnational activism', places that 'provide not only the practical infrastructure required by transnational NGO networks, but also a political climate that is not too hostile toward civil society activism’ (Piper \& Uhlin, 2004, p. 14).

More funding and international changes led in the 1980s to far more non-governmental activity in Asia. Moreover, there was a shift in focus as political repression lessened and there was a growing interest and concern with various marginalised groups such as ethnic minorities and women (Gilson, 2008). The growth in the usage of the Internet quickened the pace of social learning and development amongst such networks (Gilson, 2008). In Southeast Asia transnational activism has been a defining feature of civil society processes, especially 
since the 1997 Financial Crisis (Caouette, 2006, p. 12). In this region TANs have produced shared identifies and a common understanding of issues, as well as generated common campaigns and proposals that can be put forward during regional and international gatherings and implemented both at the regional and national levels (Caouette, 2006, p. 12).

Furthermore, TAN activism has connected grassroots NGOs' struggles to a broader set of issues and struggles, thus amplifying the work being performed at the local level in the region. Not only have TANs come to be accepted by the states of the GMS region, but they now carry with them a much more international focus and demonstrate the confidence to work with external groups (Gilson, 2008). Simultaneously, groups are no longer simply working alone, but increasingly are collaborating at other regional and international levels in order to gain greater leverage and strengthen their own claims (Gilson, 2008).

The development of NGOs in Cambodia and Thailand has followed different strands depending on the socio-political situation in these countries. NGOs have emerged in these countries when the political environment has been relatively open and free from rigid State control (Pednekar, 1995). In Thailand, which has enjoyed longer periods of political stability and political freedom, local NGOs are the most diversified in mainland Southeast Asia and are now a force capable of creating social change. NGOs in Cambodia are independent of the Cambodian government in part because most domestic NGOs were formed during the United Nations Transitional Authority in Cambodia (UNTAC) period of the early 1990s. The UNTAC period followed Cambodia’s return to democracy after the 1993 elections. During the 1990s Cambodian NGOs received financial support from international NGOs, donor agencies including various UN bodies, and governments of developed countries. Brehm (2004) argues that the Cambodian NGO sector has emerged in the mirror image of international NGOs since the opening up of the country in 1991. Cambodian NGOs are now successfully filling the social welfare gaps that emerged in the country after decades of conflict (Brehm, 2004, p. 3).

Religion has also played a major role in the proliferation of NGOS in Southeast Asia. In Thailand the Christian church is fully recognised by the Thai government and, as argued by Horstmann (2011), benefits from religious freedom in the country. This religious tolerance has motivated the presence of multiple Christian missionary agencies in Bangkok and Northern Thailand, from where they provide essential aid and services for Thailand and neighbouring countries. Large international NGOs such as World Vision International have 
head offices and field offices throughout Thailand and neighbouring GMS countries, and Christian TANs such as Chab Dai also have a strong presence and campaign reach throughout the region.

In Thailand, since the atmosphere of suspicion in the 1970s when, during the height of the Communist Party of Thailand's insurgent activities, grassroots-level NGOs were accused of being communist front organisations, the NGO-government relationship has come a long way to at least the beginnings of sustained coordination (Pednekar, 1995). Recent decades have seen TANs in the GMS region play an increasingly influential role in framing the debate around a wide variety of international policy concerns (Ratner, 2003, p. 75). The government of Thailand has accepted that NGOs do not work against the system and that they are often effective in overseeing projects at grassroots levels (Pednekar, 1995). NGOs too are beginning to accept that they alone provide no alternative to development and that their job is to complement the work of government and official donor organisations (Ruland and Ladavalya, 1991, p. 58). The development of Thai NGOs has run parallel with recent socioeconomic changes. The initial wave of NGOs concentrated on health, literacy and economic activities as a means of promoting overall human development (Pednekar, 1995). Securing funding will become a more challenging task for Thai NGOs as external funding which, according to one estimate, accounts for 70 - 90 per cent of the budget of most NGOs, is declining (Pednekar, 1995). With its rising economic prosperity, Thailand is receiving significantly lower funding from external agencies (Pednekar, 1995).

In most cases in Southeast Asia, TANs are interested in creating linkages and coalitions among diverse types of actors operating on different scales (local, national, and international) in order to respond to various political contexts (Turner \& Caouette, 2009, p. 965). Turner and Caouette also highlight the fact that there are a number of dilemmas and choices when transnational networks seek to bring local perspectives to the regional and global scales (2009, p. 965).

\section{Measuring the effectiveness of transnational advocacy networks}

The term 'effectiveness' is a complex one and the term's meaning when applied to analysing advocacy networks provides a challenge for advocacy network staff and scholars alike. TANs rarely conduct research projects to monitor and evaluate the effectiveness of their programs and campaigns. This poses inevitable problems for measuring the effectiveness of advocacy 
network collaboration and the perceived or actual success of their collective campaigns. Furthermore, in ignoring the question of network and campaign effectiveness, networks are also ignoring questions of accountability in TANs. Accountability in this sense refers to the networks' accountability to those they claim to support, that is, the recipients of their campaigning, as well as the international donors who fund their advocacy work. Atkinson and Scurrah suggest that there are two aspects to the issue of organisational accountability accountability to those who fund and support them, and accountability to those whom they wish to help (2009, p. 214). There is also a significant and powerful informal accountability that these organisations have to the members of the public (Atkinson \& Scurrah, 2009, p. 214). Unless an organisation can maintain the trust and good-will of those who donate money to it or support its campaigns, its ability to function and its financial viability will be undermined (Atkinson \& Scurrah, 2009, p. 214). Foreman suggests that accountability is a function important to any governance structure and that, from a top-down perspective at least, NGO boards hold staff accountable to the mission and principles of the organisation while, in turn, NGO governing boards must be accountable to multiple stakeholders - donors, partner organisations or members, and the poor or the beneficiaries of the NGOs' work (1999, pp. 179 - 180). Critics such as Hulme and Edwards (1997) highlight the obstacles to having a broad base of stakeholders and suggest that NGOs focus too much on the demands of donors and the conceptions of 'accountability' developed by donors.

Schweigert argues that questions of effectiveness are part of a fundamental human effort to make sense of experience, an effort that is necessary for any understanding of reality and at the same time an effort that is always problematic (2006, p. 419). It is problematic not merely because human experience is endlessly extensive but because causal understanding in itself is ultimately a leap from evidence to understanding and a leap that requires, in the difficult cases that concern scientists and evaluators, some method to assure the inferential leap is justified (Schweigert, 2006, p. 419). Consequently accountability based on standards of effectiveness appeals to a criterion that rests on a problem requiring methodological solution, and conversely, effectiveness cannot be reduced to the straightforward administrative function of accountability despite their similarities (Schweigert, 2006, p. 419). Atkinson and Scurrah in discussing the question of effectiveness, pose the important question - What characterises an organisation that can be regarded as legitimate, as usefully adding to the debate about issues in the South (or any other issue) from one that cannot? They argue that the characteristics would include having knowledge that is solidly based on research and/or 
experience, being recognised by other legitimate bodies as having useful knowledge or expertise to bring to the debate, and being sensitive to the views of those who are being spoken for or about (Atkinson \& Scurrah, 2009, p. 208). The scholars stress, however, that this route to legitimacy through democratic effectiveness or usefulness gives a 'voice but not a vote' and 'it conveys the right to speak, to have views heard, but not the right to take part in decision making' (Atkinson \& Scurrah, 2009, pp. 208-209).

Other scholars suggest that better organisational evaluation is not merely a matter of better or more measurement (Ostrower, 2005). Without a clear conception of effectiveness, organisations cannot assess, quantitatively or otherwise, how close they are to the mark, and thus risk adopting measures first and then adjusting their conceptions to fit the measures (Ostrower, 2005). With careful discernment of organisational aims and values, organisations can take better advantage of continual improvements in evaluation methods and designs and avoid being attracted away from their fundamental purposes by new technologies of data collection, new methods of analysis, and anecdotal accounts or program success (Ostrower, 2005). In today's world NGOs are hard-pressed to know what they have achieved in their advocacy work, and hence what they should be accountable for (Hudson, 2001, p. 339). Organisations balance and prioritise their relationships with other organisations on the basis of values, whether these values concern profit-maximisation, increasing market-share, empowering the poor, or generating transnational solidarity (Hudson, 2001, p. 344). More precisely, the ways in which organisations balance and prioritise their relationships with other organisations reflect what their real, in contrast to simply stated values are (Hudson, 2001, p. 344).

The prevailing view in the networking literature has been that interdependent groups of two or more organisations that consciously collaborate and cooperate with one another are more effective at providing a complex array of community-based services than the same organisations are able to do when they go their own ways (Alter and Hage, 1993). Cooperation is particularly appealing when the profit motive is absent because the potential downsides of cooperation such as reduced autonomy, shared resources, and increased dependence, are less likely to be seen as a threat to organisational survival (Provan and Milward, 2001, p. 415). 
Assessing the effectiveness of TANs is not an easy task and assessing the effectiveness of a network is much more complex than evaluating that of a single organisation (Provan and Milward, 2006, p. 416). A significant challenge lies in the fact that the analysis of multiple organisations requires dealing with multiple sets of constituencies, and the joint production of services may satisfy clients with multiple needs but it may also raise problems regarding resource sharing, political battles and so on (Provan and Milward, 2001, p. 416). Measuring TAN effectiveness therefore is not a straight forward task and is rendered even more complicated by competing internal and external factors.

\section{Findings: Measuring anti-child trafficking TANs' effectiveness}

\section{Barriers to measuring TAN effectiveness}

The design of the interview questionnaire for this study took into consideration the fact that most TANs would not have regular monitoring and evaluation activities in place to measure their processes and outcomes. Because of the fluid nature of TANs, and their unique and often changing structures, TANs would probably spend more time and resources managing internal relationships rather than expending energy on measuring the quality of these relationships and their campaign achievements. Thus the interviews contained questions to gauge TAN experts' perceptions on what they believed were areas of effectiveness, whether that be solid relationships amongst partners, effective resource distribution, information sharing, or campaign reach. The interviews revealed a number of key elements of effectiveness that provide valuable insight into the TAN effectiveness question.

More data might be available on the effectiveness of TANs and their campaigns if monitoring and evaluation activities were undertaken regularly. However, for all the TANs observed for this research, these activities were rare. As initially hypothesised, research participant interviews demonstrated that there was little attention among TANs to systematically assess the effectiveness of direct and indirect prevention and advocacy efforts. Anti-trafficking programs and projects were often designed by those running the organisations without baseline data and little research initially went into the planning and implementation of a significant number of projects. Many of the projects had no reported outcomes that were directly related to reducing the number of victims trafficked. In reporting on their work NGO networks often referred to activities that took place and the number of participants involved, but there was no attached measurement of how these activities had been beneficial and to 
whom. Without measures of attitude change or changes in the public's knowledge of trafficking it was unknown whether the programs were having any effect and were an efficient use of donor funds. When interventions were developed without sound methods for assessing their effects it was possible that they were ineffective or, worse, had unintended negative effects. Yet campaigning without monitoring and evaluating the impact of the campaigns seemed to be the norm in a significant number of TANs observed for this research.

A problem for TANs in measuring network and campaign effectiveness was that a significant amount of TAN campaigning consisted of 'awareness raising', which was extremely difficult to evaluate in terms of reach and impact. Awareness raising activities had historically avoided monitoring and evaluation analysis by TANs due to the difficulties in quantifying their impact on the public. Research participant interviews highlighted the fact that after two decades of 'awareness raising' of human trafficking in Western countries a fatigue had developed amongst the anti-trafficking community regarding the usefulness of these awareness raising campaigns. Some anti-trafficking experts were very critical of the ambiguity of trying to enhance the Western world's 'awareness' of human trafficking at all, and believed that the world was now, as an expert stated, “well aware” of the trafficking problem. In referring to the recent Body Shop anti-sex trafficking campaign, a research participant had the following criticism of awareness raising campaigns, conducted in Western countries, on sex trafficking:

I'm not completely sure that rubbing yourself with ginger after you've taken a shower is really going to help too much but the Body Shop wants that. But it's hard then to move to "what has actually happened?" No one is ever held responsible for programs. We ask - "what are you doing?” The answer is "oh we're raising awareness". Maybe twenty years ago you were raising awareness. I'm not sure there is much of an impact.

Experts also criticised other 'awareness raising' activities such as the targeting of middle range and higher end hotels in anti-sex tourism and anti-sex trafficking campaigns:

The Accor group of hotels has taken a strong stance on child sex trafficking. But how many paedophiles were taking children to the Accor hotels to begin with? Generally they go to 2 star hotels. It's nice that they did this but there is little impact. 
These examples highlight the importance of strategic planning when developing antitrafficking campaigns. As the examples suggest, it is important for TANs to consider who anti-trafficking awareness raising campaigns are designed to target. Misguided campaigns such as in the examples provided above mean that TANs waste valuable donor funds and miss reaching important target audiences. These examples also highlight the challenges for TANs in measuring the effectiveness of campaigns that cannot truly be quantified. The fact that experts in the GMS were already critical of the validity of the campaigns suggests that an evaluation of their effectiveness would result in rather dismal findings. On the flip side if more TANs monitored and evaluated their campaigns and project work they may find some hard evidence that they are making an impact, or achieving very little, and could subsequently be able to better direct their advocacy efforts.

With these and other barriers to measuring and evaluating the effectiveness of TANs in mind, such as the lack of funding and resources for performing monitoring and evaluation, during data collection I endeavoured to identify other means of conceptualising TAN effectiveness. The research participant interviews highlighted a number of key TAN effectiveness 'elements'. These 'key elements' can be understood as the core principles highlighted by experts as essential for TANs to ensure their sustainability and effectiveness. Not all antitrafficking experts were unanimous on the key elements and there was some dissent particularly regarding the importance of the TAN having a sound structure as a requirement for TAN success. However, overall there was consensus that these key elements were essential for TAN success and that if networks were to thrive and be sustainable they must incorporate these principles into their structures and daily practices. The following section of the article summarises a select number of these key elements.

\section{'Key elements' of TAN effectiveness}

Key Element 1. TAN partners need to share common anti-trafficking values and goals. A commonly expressed sentiment in the interviews was that in order to be effective, TANs must incorporate members with similar anti-trafficking values and goals. Anti-trafficking experts emphasised this point repeatedly and suggested that it was 'perhaps the most important principle for successful advocacy networking'. One expert explained that his network believed so strongly in the importance of shared values and commitment to antitrafficking work that an affiliation process had been designed for new partners wanting to join the network. During this affiliation process NGOs had to prove their values, their 
commitment to anti-human trafficking activities, their knowledge of human trafficking and their enthusiasm to conduct anti-trafficking activities. The network would assign NGOs a number of tasks to perform to 'test' whether NGOs had the values, capacity and resolve to do the work prior to organisations becoming affiliated with the network. This may appear an obvious key element to TAN success, but experts lamented the fact that NGOs frequently sought to join TANs without demonstrating an adequate commitment to the TAN. Some NGOs sought to leverage off the TAN without reflecting on what the NGO could bring to the TAN in terms of skills and knowledge. Affiliation processes were therefore a positive means of determining NGOs' commitment to the TAN and its anti-trafficking campaign activities.

Values and anti-trafficking commitment were two themes closely linked by research participants. They emphasised the point that NGOs were not simply 'good' just because they were NGOs. NGOs must prove their mettle and their commitment and values in their campaigning activities:

We need to find partners with strong skills and commitment to do the activities. If you don't have commitment how can you do it? So we talk openly amongst the partners about this. If we have commitment we have a strong voice. If there's no commitment there's no voice.

The interviews supported another hypothesis, which was that organisations form partnerships in TANs because they believe that through uniting their values and resources, they will have a wider campaign reach. A common thread in the interviews was the idea that, as one interview participant stated, 'united we're going to make a difference'. If organisations worked independently of each other, 'those small delicious projects', as one expert stated, would 'not achieve much'. It was from this common commitment, vision, and shared value system that organisations found partners to work with and that TANs developed:

\footnotetext{
We always ask ourselves - How do we take what works and doesn't work and do that next step? We have partners and we can grab their hand two at a time and walk down the path together. It's a case of ensuring it's not us who is imposing our views on them but collectively coming to the decision that we should go a certain direction because this organisation offers something, and this other organisation offers something. To get to that point we need to work together. It's a clumsy process sometimes. If you don't have a vision and a sense of where you're going, some organisations never get anywhere.
} 
Keck and Sikkink have pointed to two factors concerning the political outcomes of TANs: Issue and actor characteristics (1998, p. 26). The researchers argued that networks tend to be most successful when they mobilise around value-laden issues "involving bodily harm to vulnerable individuals, especially when there is a short and clear causal chain assigning responsibility” (Keck \& Sikkink, 1998, p. 27). Therefore successful campaigning and mobilisation is likely to occur around the first type of issue involving physical harm to innocent persons - in the case of this study, children. The TANs studied here focused a significant proportion of their campaigning on the child victim of trafficking and potential victims of trafficking. Interview data reflected the desire to network from a programmatic point of view. In order to improve child protection systems it was necessary to have interested groups working together to build functioning systems in countries where such systems were still in a state of underdevelopment:

It's trying to develop, work with other partners to develop, standards for child protection and a common understanding of what is child protection because it's not always an area that's understood. There's not a lot of consensus, and in terms of looking at building a system you obviously need coordination between partners, it makes sense from a programmatic point of view. It makes sense that you need people, especially in the area of child protection, you need coordination, you need people working together, you need all the systems working together, you need people who have an understanding of the issue. Because by nature it's a very multisectoral area you have to have people working together if you actually want to improve the system.

Key Element 1 therefore demonstrates that for TANs to be effective, partners must have a shared commitment to anti-trafficking activities and shared cosmopolitan values. TANs preferred partners with experience in the field and expertise in anti-trafficking advocacy. Some TANs had stringent affiliation processes to check that these values and commitment were present. This was less frequently the case with smaller NGO networks that had in many instances already worked collaboratively with network partners on previous campaigns and adopted more fluid structures 
Key Element 2. TANs should include not just NGOs but also UN agencies and government partners.

In addition to the importance of having shared values and commitment, anti-trafficking experts suggested that TANs were most effective when they incorporated partners from NGOs, UN agencies, and governments. There was consensus in the interviews that interagency collaboration across all sectors was crucial to effective advocacy against child sex trafficking. For example, in order for agencies to work effectively on victim protection, TANs needed to first have a good working relationship with the police so that they could collaboratively work in a way that best assisted the trafficking victims. Inter-agency networks such as UNIAP, by virtue of their history and structure, were already composed of partners from NGOs, UN agencies and governments and were therefore already collaborating across multiple sectors. The call for improved government-NGO-UN agency collaboration came more from the various NGO networks that concentrated a large proportion of their work on protecting and rehabilitating victims. Research participants from all types of NGO networks expressed a desire to work with UN and government partners either regularly or on an ad hoc basis when the need arose, even though this kind of inter-agency collaboration was often described as a 'difficult' and 'tedious'.

Interviews for this study revealed that TAN members desire inter-agency collaboration for a number of reasons. Partnering with UN agencies in TANs enabled NGO members to gain access to the UN's expertise and capacity on trafficking, training programs and access to governments. The UN often represented NGOs in national and regional fora, therefore by partnering with the UN, NGOs were ensuring that their 'voice' was heard at a higher political level. This was particularly important for Southern NGOs that frequently lacked a voice with their own governments and in international fora. Partnering with UN agencies also sometimes enabled NGOs to source new avenues of funding.

The interviews revealed that NGOs collaborated with governments in TANs in order to train government staff on human trafficking issues and improve government capacity to fight trafficking. NGOs also networked with GMS governments to improve anti-trafficking policy and legislation and facilitate collaborative victim rescues and arrests of paedophiles. There was consensus in the interviews that it was also important for NGOs to network with UN agencies and governments in order to be able to better plan for victim services. One expert 
explained how the network she was involved in worked closely with the police on child rescues and paedophile arrests. When the network was made aware of a paedophile in the Thai locality the staff would immediately call their police counterparts and, working with the witness (often a child living on the street) they would organise the arrest of the paedophile. The expert explained that local children 'did not trust the police' so would not report cases of abuse directly to police but, rather, would contact her organisation.

Research participants from UN agencies explained that from the UN perspective, partnering with NGOs was essential in order to have access to child victims of trafficking and a presence 'on the ground'. NGOs were the organisations predominantly responsible for managing protection shelters for trafficked children. NGOs, particularly grassroots NGOs, had a strong presence and considerable expertise working in the field with victims and at-risk groups. Without links to grassroots NGOs, the UN's access to these aid beneficiaries and trafficking victims was greatly hampered.

Key Element 2 therefore demonstrates the importance of engaging partners from all antitrafficking sectors (NGOs, UN agencies and governments) in TANs against child trafficking. In partnering with members from diverse sectors, TANs are able to leverage different skills sets and expertise to improve campaign reach and to have a stronger political voice. Through partnering with diverse groups across all sectors TANs are better able to plan for, and meet, the needs of victims and are therefore more effective at achieving their network goals.

Key Element 3. Anti-trafficking networks should balance the 'voice' of Northern and Southern NGO partners in TANs.

As discussed in Key Element 2 effective TANs consisted of partners from all sectors, including NGOs from both the North and the South. North-South collaboration was a key aspect of network politics, however, while the desire to network across all sectors appeared a truly voluntary commitment, some networking relationships with grassroots NGOs were considered 'forced' partnerships by a number of research participants and a necessity rather than a truly voluntary decision. The attitude expressed by some Northern experts of networking with Southern organisations as "just getting on with it” suggested that collaborative North-South relationships in TANs did not always progress smoothly. Nonetheless North-South NGO networking remained a necessity for TANs to effectively 
identify, access and assist child trafficking victims. Key element 3 touches on the important theme of 'voice' within networks and explains how a balance of power and voice is essential if TANs are to be effective.

Representatives from inter-agency networks expressed a desire to see more Southern NGOs represented in TANs and lamented the fact that the grassroots NGO voice was 'represented' by larger peak and global NGOs in international fora. While inter-agency networks had devised strategies to ensure that the voice of the Southern NGOs was heard, for example, through rotating chairs within national taskforces, there was still frustration that the structure of the network did not allow for Southern NGOs to have a stronger voice in the TAN. Southern partners expressed a desire to have a partnership in TANs, as one expert stated, 'based on genuine dialogue, where their own experience is recognised and where Northern NGO partners are more transparent about the decision-making processes within TANs'.

Some TANs, particularly the larger NGO international networks, appeared to maintain a customer-client attitude to networking with Southern NGOs. Southern NGOs enabled Northern NGOs to access child victims of trafficking while Northern NGOs provided Southern partners with important resources and funding. A core problem in equalising the power balance between the Northern and Southern network members lay in the unequal resources between the two groups. Northern NGOs were significantly better funded and resourced than their Southern counterparts. Instances of negative networking between Northern and Southern network members due to resource related tensions sometimes led grassroots NGOs to leave TANs. Research findings suggest that the power dynamics in TAN relationships may reinforce organisational hierarchies and patterns of exclusion. To counter this some networks, particularly inter-agency networks, had systems in place to prevent instances of North-South conflict. Instead of merely funding Southern NGOs and, as an expert stated, 'leaving them to their own devices', these networks would endeavour to 'hold the hand' of Southern NGOs and train them 'collaboratively' to 'increase their capacity'. Some scholars such as Smith (2002) argue that this kind of conflict is not without its benefits. Smith has argued that gaps between Northern and Southern members persist, but that some good North-South relationships can arise from this kind of forced partnership for a common good (2002, p. 505). 
Key Element 3 therefore demonstrates the importance of balancing North-South voices in TANs. Key Element 3 touches on some of the obstacles to promoting cosmopolitan values. Even within networks, whose aim is to promote these values, there are internal issues surrounding voice and equality. Before networks can hope to successfully promote equality they must first balance their own internal power relationships.

Key Element 4. TANs should be composed of partners with diverse skills, not partners doing "exactly the same kind of work".

Research participant interviews revealed that TAN strength is derived from the diversity of its members. Moreover, while organisations may want to network, competition occurs between partner organisations and this can lead to instances of conflict amongst network members that regularly compete over donor funds, branding and reputation.

The interviews with anti-trafficking experts brought to light the importance of organisational diversity in networks as a means of reducing instances of conflict between partner organisations. Research participants couldn’t 'emphasise enough' that anti-trafficking TANs 'should partner with organisations with complementary skills, not with organisations doing exactly the same kind of work'. Two decades of experience in the anti-trafficking advocacy field has taught TAN staff that it is better to diversify members to increase capacity and capability rather than have partners with similar skills sets and performing similar tasks, which only led to activity repetition and conflict between partners. Diversity of network partners meant, for example, that some NGOs could concentrate on the protection of trafficking victims while others focused on child trafficking prevention activities. Through operating in TANs, partners were thus able to better meet the legal, health, shelter and service needs of victims.

Although victim protection was the main focus of TANs' campaigning, network partners spent considerable time performing other activities such as training police, working to improve human trafficking legislation, lobbying governments, organising and conducting rescues in conjunction with police, and conducting awareness raising campaigns. When faced with a large number of victims, networks needed to have the capacity and resources to deal with all aspects of victim protection and rehabilitation. Performing all tasks simultaneously was beyond the scope of any individual organisation's expertise and capacity. When 
organisations operated in TANs with partners with different areas of expertise they were able to better meet the needs of the victims and target their campaigns more broadly. This meant that the networks’ impact was stronger and that victims’ needs were better met.

I spent six months working for an international NGO in Thailand, where I was able to witness first-hand the tensions that can arise amongst TAN partners. The NGO I worked for has a very good reputation in the region and attracts significant amounts of international funding for its anti-trafficking advocacy and policy work. It is similar in size and budget to another international NGO that also has a strong presence in the region. The two NGOs have historically worked together on anti-trafficking campaigns, however, these partnerships have not always progressed smoothly. It was difficult to divide tasks between the two NGOs, who ultimately competed for reputation and donor funding, and therefore both wanted to enhance their branding. Conflict arose primarily over task-distribution, and also over product output, funding arrangements, and, indeed, campaign goals. Ultimately, these tensions were smoothed over by the individuals who represented the NGOs, and the better the relationships between NGO representatives, the more effective the campaign would progress.

Some anti-trafficking TANs in the GMS had processes in place to ensure that partners were complementary to existing members in the network and not performing exactly the same activities or services. As this expert's comment suggests, network representatives placed considerable emphasis on the value of organisations partnering with organisations that complemented their anti-trafficking work:

There's really no point hooking up with someone who is doing exactly the same thing. I can't overstate that. It would be far better for you to find someone who is doing something slightly different and which complements what you're doing.

Research participants also explained that by networking with organisations with complementary skills they were also able to prevent disruption to network function when a member left the TAN. Diversity of TAN partners provided a kind of safety net for when partners left the network and a gap in expertise or victim services was created by partner attrition. In those TANs that possessed diversity in partner membership, other partners could quickly step in to fill knowledge and service gaps. 
Key Element 4 therefore demonstrates that a key principle to effective advocacy networking against trafficking in the GMS is that TANs must consist of partners with complementary skills, rather than partners with similar expertise, or performing similar anti-trafficking activities. This is important for ensuring that networks can assist large numbers of beneficiaries with diverse needs. By networking with organisations with complementary skills, TANs could also ensure that there was less chance of duplication of programs and services, that important campaign messages were streamlined, that a gap was not left when an organisation decided to leave the network, and that instances of conflict between network members, who were naturally in competition over funding, branding and prestige, were avoided. Diversity of TAN members also meant that campaign reach and impact with GMS citizens and governments was stronger.

Key Element 5. Networks should have strong structures and a secretariat.

Research participants revealed that for TANs to be effective, they must have sound and transparent structures. Interviews with anti-trafficking experts reflected a preference for structured networks with a secretariat or a central coordinating office that was responsible for communicating TAN activities and relaying information between TAN partners. While such a strong structure may invoke impressions of cumbersome, conservative, bureaucratic structures, this was not often the case in anti-trafficking TANs in the GMS. In this region, the TAN secretariat or coordinating office acted as the backbone of the advocacy network and provided the coordination and communication centre that the TAN required in order to share information with its diverse partners and coordinate campaign activities.

Anti-trafficking experts suggested that it was beneficial for TANs to have terms of reference, individual ownership of tasks, a strong secretariat, rotating chairs, joint leadership plans, and the flexibility to change the direction of the TAN and its activities. This structure seemed to be most popular amongst networks that needed it, for example, inter-agency networks that incorporated partners from government, NGOs, and UN agencies and that focused on developing laws and policy on prosecution and that had specific targets for achieving certain policy goals. Some participants in the more structured networks such as inter-agency networks emphasised the importance of designing specific network rules, for example, through memoranda of understanding or agreements about how the organisations were to interact and treat each other, as well as their roles and responsibilities in the TAN. 
The inter-agency network, UNIAP, provides a good example of the importance of sound structure to TAN effectiveness. UNIAP was established in 2000 with a mandate to strengthen the coordination of organisations in the fight against trafficking in the region and to implement a wide range of protection, rehabilitation and reintegration programs. In 2004, UNIAP brought together the governments of Thailand, Laos, Myanmar, Cambodia, China and Vietnam, thirteen UN agencies and many local and international NGOs to establish the Coordinated Mekong Ministerial Initiative Against Trafficking (COMMIT). COMMIT was the first regional instrument to make a serious effort to institutionalise a multi-sectoral approach to make certain that the responsibilities and commitments made in the memoranda of understanding between GMS governments were implemented in accordance with international norms and standards. The articles within the Subregional Plan of Action specifically referred to the need for governments to work together with international organisations and NGOs to close all avenues of exploitation (Jayagupta, 2009, p. 236). In Thailand, a number of memoranda of understanding have been developed to strengthen interagency coordination. The Memorandum of Understanding on the Operations and NonGovernment Organisations Engaged in Addressing Trafficking in Children and Women focused on cooperation between government agencies and NGOs, while the Memorandum of Understanding on the Operational Guidelines of Non-Government Organisations Concerned with Cases of Trafficking in Women and Children addressed cooperation and action within the NGO community (Jayagupta, 2009, p. 233). The memoranda of understanding provided for operational taskforces on rescues and suppression of trafficking crimes, and comprised representatives from government agencies and NGOs forming a multi-disciplinary team (Jayagupta, 2009, p. 233). UNIAP has proved to be a highly effective network for the coordination of a significant number of the diverse anti-trafficking organisations and networks in the region. UNIAP not only hosts COMMIT but also acts as a coordinating office for the GMS governments, many Northern and Southern NGOs, and UN agencies, providing them with platforms for discussion, coordinating workshops and seminars, and acting as a central resource and information hub. TAN structure was crucial to UNIAP and it drew heavily on its structure to determine inter-agency cooperation, partner tasks and responsibilities, the development of policy and legislation, and trainings. Without its sound structure, secretariat, and its mandate to coordinate anti-trafficking stakeholders, UNIAP would have not been able to make the significant contributions it has already made to the GMS region including government cooperation, the development of memoranda of 
understanding between governments, government capacity building, and the streamlining of human trafficking campaign messages in the region.

Key Element 5 demonstrates that the structure of the TAN determines the important flows of communication between network partners. This constant flow of communication and information keeps TAN partners fully cognisant of their roles and responsibilities within the network, and network activities and campaigns. Sound network structure means that network partners can have a 'voice' in the TAN by communicating to other partners directly or through the TAN's secretariat or other coordinating office.

\section{The centrality of TANs in combating child sex trafficking in the GMS}

When TANs are successful in incorporating the key elements discussed in previous pages, they can be extremely effective in protecting children, performing valuable advocacy, and providing victim services. In the GMS transnational advocacy networking against child trafficking has enabled organisations with different mandates and expertise to share skills and capacity for a broader and improved response to child trafficking including prevention, protection, and prosecution activities and rehabilitation of victims. In addition, by networking against this problem, TANs have been able to have a stronger voice in lobbying for new child trafficking policy and legislation, and improved opportunities for working collaboratively on improving child protection systems in the GMS. Most importantly, transnational advocacy networking has contributed to a redistribution of knowledge, power, influence and material resources from the rich North to the core Southern actors working on the ground in local NGOs in the GMS.

Advocacy networking against child trafficking in the GMS has helped to ensure a number of important benefits for victims. Foremost amongst these has been the benefit that victims are able to access a wide range of services. TANs have facilitated the streamlining of victim services and once victims are identified, TANs have been effective in referring victims to partner agencies for a range of protection and rehabilitation services. In addition, TANs are helping vulnerable children acquire knowledge and tool sets to mitigate their risks of exploitation. 
TANs in the GMS are also facilitating effective collaboration among law enforcement agencies across jurisdictions so that bureaucratic obstacles are minimised and perpetrators of child trafficking do not escape justice. Improved prevention-oriented coordination has facilitated the involvement of all sectors of society so that anti-trafficking networks can move toward the ultimate goal of preventing the exploitation of children. In providing such victim services, and through the direct sharing of global political economy knowledge, TANs are bringing an equal level of counter-activity to a social problem that is clearly enhanced, even promoted, by the economic connectedness of the globalisation of criminal networks that sell children's sexual labour as a commodity.

A further major benefit of collaboration through TANs is that anti-trafficking campaigns can reach all corners of the globe rather than just a small geographic corner. Campaigns have been adapted and developed to target citizens not just in the GMS but also in a large number of developed countries to teach them about slavery, trafficking and ethical consumerism and make the West aware of the strict penalties imposed on those who travel to poorer countries to sexually abuse children. This expansive outreach, beyond the borders of the GMS, and the incorporation of cultural difference and engagement, reflects the essentially cosmopolitan nature of TANs and provides an important model for addressing global social problems.

Individual anti-trafficking organisations, particularly grassroots NGOs, have little 'voice' with states and the GMS community in campaigning for child trafficking prevention and victim protection. However, when organisations unite in TANs they are able to share resources, knowledge and skills and thus have a stronger campaign reach and impact in the GMS community and a stronger political voice with states. With a united voice TAN members are providing an effective buffer against child trafficking. As one expert commented, 'there is real value in coming together, the voices together are a lot more difficult to quiet than on their own'.

\section{Conclusion}

In a similar vein to the women's rights and other social justice movements, TANs in the GMS are promoting cosmopolitan notions of global justice and supporting the creation of global fora to fight child trafficking. Through conventional and unconventional advocacy activities such as rock concerts and social media campaigns, anti-trafficking TANs have been successful in broadening their appeal by reaching out to members of the public who may not 
be able to join protest marches but are willing to engage in and support 'innovative activities with a critical edge' (Kurasawa, 2004, p. 251). Further, anti-trafficking TANs' development of fora and involvement in creating new legislation have pushed the child trafficking issue onto the global social policy agenda and promoted the goal of universal child rights.

This article has discussed the importance of understanding TAN effectiveness and considering new ways of measuring TAN success and effectiveness. It has discussed barriers to measuring TAN effectiveness, and suggested that a way of manoeuvring around the difficult task of measuring the immeasurable is to examine the 'key elements' of effectiveness that TAN experts have identified. The article has discussed a number of these key elements and explained how the key elements are essential to ensuring network sustainability and success. Core principles of TAN effectiveness include inter-agency collaboration; the balancing of power and voice between Northern and Southern TAN partners; diversity in expertise and capacity of TAN partners to meet the needs of victims; and a strong and transparent network structure to ensure efficient communication flow between TAN partners. When TANs achieve these key elements, they can be extremely effective.

The success of anti-trafficking TANs has been significant but there is much more that needs to be done. Child trafficking is likely to increase under conditions of poverty, unemployment, and social and economic transition, especially in regions where there are limited legal migration opportunities. TANs continue to expend much energy keeping children's rights on key UN and government agendas. Recent successes highlight the critical importance of sustained and effective TAN practice that engages with global political, legal and economic arenas in the struggle to keep a global focus on children's rights

\section{References}

Alger, C. 1997, 'Transnational social movements, world politics and global governance', in. Smith J. (ed.), Transnational Social Movements and Global Politics: Solidarity Beyond the State, Syracuse University Press, New York.

Alter, C., \& Hage, J. 1993, Organisations Working Together, Sage, Newbury Park.

Atkinson, J., \& Scurrah, M. 2009, Globalizing Social Justice: The Role of Non-Government Organizations in Bringing About Social Change, Palgrave Macmillan, Basingstoke.

Baehr, P. 1996, Mobilisation of the conscience of mankind: Conditions of effectiveness of human rights NGOs. Paper presented at the UN University Public Forum.

Brehm, V. 2004, Autonomy or Dependence? North-South NGO Partnerships, INTRAC. 
Brusca, C. 2011, 'Palermo Protocol: The first ten years after adoption', Global Security Studies, vol. 2 no.3, pp 1-20.

Canadian Council for Refugees 2009, Trafficking in Persons. Retrieved 11 November, 2009, from http://www.ccrweb.ca/trafficking/learn.htm

Caouette, D. 2006, 'Thinking and nurturing transnational activism in Southeast Asia', Philippine Journal of Third World Studies, vol. 21, no. 22, pp. 3-33.

Caouette, D. 2007, 'Going Transnational? Dynamics and challenges of linking local claims to global advocacy networks in Southeast Asia', Pacific Focus, no. 22, pp. 141-166.

Child Wise 2007, ASEAN Child-Sex Tourism Review, ASEAN, Melbourne.

ECPAT 2006, Global Monitoring Report on the Status of Action against Commercial Sexual Exploitation of Children: Thailand. ECPAT, Bangkok.

Evans, P. 2000, 'Fighting Marginalization with Transnational Networks: Counter-Hegemonic Globalization', Contemporary Sociology, vol. 29, no.1, pp. 230-241.

Florini, A. 2000, 'Who does what? Collective action and the changing nature of authority', in Higgott,R., Underhill, G. \& Bieler, A. (eds.), Non-State Actors and Authority in the Global System, Routledge, London.

Foreman, K. 1999 'Evolving global structures and the challenges facing international relief and development organizations’, Non-profit and Voluntary Sector Quarterly, vol. 28, no. 4, pp. 178-197.

Gilson, J. 2008, Transnational Advocacy and East Asian Regionalism, University of Birmingham.

Held, D. 2002, 'Globalization, corporate practice and cosmopolitan social standards', Contemporary Political Theory, vol. 1, no.1, pp. 59-78.

Henry, L., Mohan, G., \& Yanacopulos, H. 2004, 'Networks as transnational agents of development', Third World Quarterly, vol. 25, no. 5, pp. 839-855.

Horstmann, A. 2011 'Sacred networks and struggles among the Karen Baptists across the ThailandBurma border', Moussons, vol. 17, no. 1, pp. 85-104.

Hudson, A. 2001, 'Transnational Advocacy Networks: from legitimacy to political responsibility?' Global Networks, vol. 1, no.4, pp. 331-352.

Hudson, A. 2002, 'Advocacy by UK-based development NGOs', Non-Profit and Voluntary Sector Quarterly, vol. 31, pp. 402-418.

Huijsmans, R. 2008, 'Children working beyond their localities: Lao children working in Thailand', Childhood, vol. 15, pp. 331-353.

Hulme, D. \& Edwards, M. 1997, Donors and States: Too Close for Comfort, St Martin's Press, New York.

Jayagupta, R. 2009, 'The Thai Government's repatriation and reintegration programmes: Responding to trafficked female commercial sex workers from the Greater Mekong Subregion', International Migration, vol. 47, no. 2, pp. 227-253.

Keck, M., \& Sikkink, K. 1998, Activists Beyond Borders, Cornell University Press, London.

Keck, E., \& Sikkink, M. 1999, Transnational Advocacy Networks in International and Regional Politics, Blackwell Publishers, Oxord.

Kristof, N. 1996, April 14, 'Children for Sale - A Special Report: Asian Childhoods Sacrificed to Prosperity's Lust' The New York Times.

Kurasawa, F. 2004, 'A cosmopolitanism from below: Alternative globalisation and the creation of a solidarity without bounds', European Journal of Sociology, vol. 45, pp. 233-255.

Loh, F., \& Ojendal, J. 2005, Southeast Asian Responses to Globalisation: Restructuring Governance and Deepening Democracy, Nordic Institute of Asian Studies, Copenhagen.

Marshall, P. 2001, Globalisation, Migration, and Trafficking: Some Thoughts from the South-East Asian Region, [Occasional Paper], UN Inter-Agency Project on Trafficking in Women and Children in the Mekong Sub-Region No.1.

Morvaridi, B. 2005, 'Contentious development issues and transnational networks', In Harrison, G. (ed.), Global Encounters: International Political Economy, Development and Globalization, Palgrave Macmillan, Basingstoke.

Ostrower, F. 2005, 'Foundations, heal thyselves', The Chronicle of Philanthropy, Retrieved from www.philanthropy.com/free/archive.htm 
Pednekar, S. 1995, 'NGOs and natural resource management in mainland Southeast Asia', TDRI Quarterly, vol. 10, no. 3.

Peters, H. 2007, Sun, Sex and Heritage: Tourism Threats and Opportunities in Southeast Asia: UNIAP and World Vision. http://www.worldvision.org/resources.nsf/main/sun_sex_heritage.pdf/\$file/sun_sex_heritage.pd $\underline{f}$

Piper, N., \& Uhlin, U. 2004, Transnational Activism in Asia - Problems of Power and Democracy, Routledge, London.

Piotrowicz, R. 2008, 'The UNHCR's Guidelines on Human Trafficking', International Journal of Refugee Law, vol. 20, no.2, pp. 242-252. doi: 10.1093/ijrl/een013

Price, R. 1998, 'Reversing the gun sights? Transnational civil society targets land mines', International Organization, vol. 52, no. 3, pp. 613-644.

Provan, K., \& Milward, H. 2001, 'Do networks really work? A framework for evaluating publicsector organisational networks', American Society for Public Administration, vol. 61, no. 4, pp. 414-423.

Ratner, B. 2003, 'The politics of regional governance in the Mekong River Basin', Global Change, vol. 15, no. 1, pp. 59-76.

Ruland, J. \& Ladavalya, B. 1991, Voluntary Associations and Municipal Government in Thailand, Foundation Volkswagenwerk, Hannover.

Schweigert, F. 2006, 'The meaning of effectiveness in assessing community initiatives', American Journal of Evaluation, vol. 27, pp. 416-435.

Shawki, N. 2007, Understanding the Political Outcomes of Transnational Campaigns: A Comparative Study of Four Transnational Advocacy Networks, Indiana University, Indiana.

Smith, J. 2002, 'Bridging global divides? Strategic framing and solidarity in transnational social movement organisations', International Sociology, vol. 17, no. 4, pp. 505-528.

Turner, S., \& Caouette, D. 2009, 'Agrarian angst: Rural resistance in Southeast Asia', Geography Compass, vol. 3, no. 3, pp. 950-975.

UN 2000, Protocol to Prevent, Suppress and Punish Trafficking, Especially Women and Children, Supplementing the UN Convention Against Transnational Organized Crime Retrieved from http://www.ohchr.org/english/law/pdf/protocoltraffic.pdf

UN.GIFT 2012, UN Global Initiative to Fight Trafficking Retrieved 12 March, 2012, from http://www.ungift.org/knowledgehub/

UNIAP 2008, SIREN Human Trafficking Data Sheet, Retrieved 13 August, 2009, from http://www.no-trafficking.org/reports docs/lao/datasheet laopdr march08 ENG.pdf

UNICEF 2009, Child Trafficking in East and South-East Asia: Reversing the Trend, UNICEF East Asia and Pacific Regional Office, Bangkok.

UNODC 2008, The Global Initiative to Fight Trafficking, Retrieved from http://www.unodc.org/pdf/gift\%20brochure.pdf

Yanacopulos, H. 2005, 'The strategies that bind: NGO coalitions and their influence, Global Networks, vol. 5, no. 1, pp. 93-110.

Wong, D. 2004, The Rumour of Trafficking: Border Controls, Illegal Immigration and the Sovereignty of the Nation-State, Institut Kajian Malaysia dan Antarabangsa (IKMAS), Universiti Kebangsaan Malaysia.

Wylie, G., \& McRedmond, P. 2010, Human Trafficking in Europe: Character, Causes and Consequences, Palgrave Macmillan, London. 